\title{
THE EFFECT OF PROBLEM SOLVING MODEL AND SCORING TYPE OF MULTIPLE-CHOICE FORMATIVE TESTS ON STUDENT HIGH ORDER THINKING SKILLS (HOTS) ABILITY
}

\author{
Andi Taufiq Umar 1)*, Nurjannah ${ }^{2)^{*}}$, Agus Dudung ${ }^{3)^{*}}$ \\ ${ }^{1)}$ Universitas Cokroaminoto Palopo \\ 2) 3)UniversitasNegeri Jakarta \\ 1) anditaufiq847@gmail.com
}

\begin{abstract}
This research is a type $2 \times 2$ factorial design that aims to see the correlation between problem solving model and scoring type of multiple choice formative test in improving students' HOTS capability in Chemistry lesson. Type of scoring test is divided into two sub-variables that scoring by scores and scores are appropriate while the learning model consists of problem solving model and direct learning model. The student's HOTS capability consists of three stages of cognitive namely analysis, evaluation, and synthesis by using choice of choice test with several HOTS answer choices that have been validated by experts and panelists. The population in this study is all students of SMA Negeri in East Luwu regency. Sampling was done by cluster random sampling with total sample of 80 students who were integrated into empathy groups consisting of 20 samples per group. The result of analysis shows that FO value in main effect test and interaction effect is bigger than Ftable value is 3,968 which show the influence of interacation between problem solving model and scoring type to students's HOTS ability.
\end{abstract}

Keywords: Problem-solving model, scoring type, HOTS capability

\section{INTRODUCTION}

Education is the transform of intellectual, spiritual and humanist values that must be structured constructively and actualized in reality. But in reality, the quality of education in Indonesia is still relatively low. There are many things that cause the low quality of Indonesian education, among others, the low quality of teaching devices, uneven teacher welfare, lack of educational opportunities for some, irrelevant educational needs, and the high cost of education in Indonesia (Kholid, 2013).

Chemistry subjects are one of the disciplines that teach about the composition, structure, nature and changes of a material with a high level of understanding and analysis so that the low quality of teachers, infrastructure in learning can affect the low learning achievement of students in chemistry subjects.

The low achievement of student learning can be seen in a study on chemistry subjects on the mastery of the chemical material concepts in the National Examination due to many concepts that fail to be mastered, students fail to interpret tables of $\mathrm{pH}$ indicators, diagrams and difficult to understand the problem of multiconcept (Adlim, 2017).

The other factors that cause students difficulty in learning chemistry are the low curiosity of students during the learning process, the low motivation of students in learning new material, the low strengthening of basic concepts of chemistry, learning methods, and less varied test instruments. Therefore, it takes a practical handling in providing solutions to this problem. One alternative that is able to provide an improvement to student achievement in learning is to provide an 
effective learning model in accordance with the abilities and characteristics of students.

According to Cratwohl Anderson, the ability of students in mastering teaching material is classified based on the level of students' cognitive levels, namely the level of knowledge, understanding, application, analysis, evaluation and synthesis. The first three levels are included in the cognitive category of low order thinking skills (LOTS) while the next three levels are included in the category of high order thinking skills (HOTS). Analytical and abstract chemistry studies require students to be able to solve problems at the HOTS-type cognitive level.

One learning model that is considered effective in improving students' HOTS chemistry is by applying problem solving learning models. According to Latifah, the problem solving model is basically a learning model that directs students to learn to use scientific methods or think systematically, logically, regularly, and thoroughly.

The goal is to acquire cognitive abilities and skills in problems solving rationally, straightforwardly, and thoroughly. For that, the ability of students in mastering concepts, principles, and generalizations and insight (deep understanding) is needed. This learning model is more oriented towards students during the learning process takes place. The stages of learning this model are starting with identifying problems, setting goals, exploring problem solving strategies, implementing the right strategies, and seeing and learning from the results obtained. (Susiana, 2014)

There are two types of scoring in the multiple choice test form used in this study, namely the correct score and scoring with punishment score. The type of scoring used by the teacher is the correct score where the scoring only sums up the whole correct answer. This type of scoring will allow students to speculate to guess the correct answer. So most students assume that multiple choice tests are easier to work than other test forms.

There are two things that become factors so that students can guessing in multiple choice tests, the first is inability of students to choose the right answer as a result of the failure of mastering the material by students. Secondly, the mismatch of difficulty level questions about their ability. Guessing behavior is one of the sources of measurement errors in tests, especially the test of achievement of learning outcomes. In addition, with correct score scoring it would be difficult to distinguish between students who answered the questions correctly because of their thinking and students who answered the questions correctly because of the guessing behavior (Kusaeri, 2010).

To overcome these problems, other types of scoring that can be used to minimize guessing are punishment scores. Penalties are a type of scoring that provides penalties in the form of a reduction in the value of the wrong answer choice by students with the formula $-1 / \mathrm{n}-1$. (Naga, 2012)

Because of the importance effective learning models such as problem solving learning models on students 'HOTS abilities and the suspicion that punishment scores are scaled up to improve students' HOTS abilities, further research is needed on the effect of problem solving models and scoring type of multiple-choice formative tests on student's HOTS abilities. 


\section{METHODS}

This research is experimental research with factorial design type $2 \times 2$, with the aim to know the difference the effect of problem solving model and scoring type of multiple-choice formative tests and sub variable consistency in variable to dependent variable that is high order thinking ability of students in chemistry subject.

This research was held in State Senior High School 1 (SMAN !)LuwuTimur and State Senior High School 12 (SMAN 12) LuwuTimur in LuwuTimurRegancy. The time for conducting research begins in April - May 2018, even semester 2017/2018 school year.

The main characteristic of experimental research is the treatment. There are two forms of treatment that become independent variable in this research that is model of learning which is divided into 2 types, that is problem solving model and direct learning, and scoring type of multiple choice formative tests which consist of two kinds of scoring that is punishment score and correct score. Experimental with $2 \times 2$ factorial design.

Table. 1. 2x2 Factorial Design

\begin{tabular}{|c|c|c|}
\hline \multirow{2}{*}{$\begin{array}{c}\text { Soring type } \\
\text { of Multiple } \\
\text { Choice } \\
\text { Formative } \\
\text { Test (B }\end{array}$} & \multicolumn{2}{|c|}{ Learning Model (A)) } \\
\hline & $\begin{array}{c}\text { Problem } \\
\text { Solving } \\
\left(A_{1}\right)\end{array}$ & $\begin{array}{c}\text { Direct } \\
\left(\mathrm{A}_{2}\right)\end{array}$ \\
\hline $\begin{array}{c}\text { Punishment } \\
\text { Score } \\
\left(B_{1}\right) \\
\end{array}$ & $\mathrm{A}_{1} \mathrm{~B}_{1}$ & $\mathrm{~A}_{2} \mathrm{~B}_{1}$ \\
\hline $\begin{array}{l}\text { Correct } \\
\text { Score } \\
\left(\mathrm{B}_{2}\right)\end{array}$ & $\mathrm{A}_{1} \mathrm{~B}_{2}$ & $\mathrm{~A}_{2} \mathrm{~B}_{2}$ \\
\hline
\end{tabular}

The population in this research is all students of State Senior High School in Malili Districts, East Luwu regency. Students who were sampled in this study were students of class XI of SMAN 1 LuwuTimur and SMAN 12 LuwuTimur. The sample of the research was conducted by cluster random sampling technique, is sampling was done by taking samples from the population unit by taking into account all groups in the population with no attention to the individual.

The determination of the sample size in each class that was sampled in this study had a number of students between 28-29 students in each class. In order to maintain the level of data homogeneity, 20 students were taken randomly in each class of study so that the total number of students sampled in this study were 80 students.

Validity of instruments used validated by 3 experts and 20 panelists. Experts and panelists will provide assessment, correction, crosscheck of research instruments used by looking at the suitability between each item with the cognitive level at the HOTS level is C4, C5 and C6, and see how far the instrument is representative of the material and the level of student ability in accordance with prevailing standards. Expert analysis and critics and panelists were used as 
references to improve and refine the contents of this research test instrument. Analysis of expert correction results and panelists is determined using the lawshe (CVR) formula.

Test data analysis techniques of research results are carried out in two types of testing, including:

1. Prerequisite Test Analysis

This analysis is done to see the normality and degree of homogeneity of the data obtained after the study. In this test is divided into two types of test is the normality test and homogeneity test. The normality test of the data was performed by using liliefors test at the 0.05 level. This test is carried out to prove that the data obtained is normally distributed. And testing homogeneity of data is done with the aim to know that the data obtained is homogeneous. Homogeneity test was performed by using barlett test at 0.05 level.

\section{Hypothesis Testing Analysis}

After the data is known to be normal and homogeneous distribution, the research hypothesis will be tested by using Analysis of Variance 2 road or ANAVA 2 Road. In this test it will be known that the variables studied have interaction or not. The direction of this test consists of three types of main effects, interaction effect, and will be continued with the t-dunnet test if there is any interaction between the independent variables studied to the dependent variable to test the simple effect.

\section{RESULTS AND DISCUSSION}

The data obtained in the form of scores based on the results of research in the field, will be described in accordance with the variables studied are the dependent variable of students's HOTS ability on chemistry subjects, and independent variables consisting of problem solving learning model and the type of scoring pro formative multiple choice test. The scores of students's learning outcomes obtained are then integrated into each group of data based on previous research designs.

This study is composed of two independent variables, namely learning model (A) which consists of problem solving learning model (A1) and direct learning model (A2), and scoring type of multiple choice formative test (B) consisting of two types of scoring is punishment score (B1) and correct score (B2). Based on the combination of these variables, there are 4 (four) groups in this study that is group with problem solving learning model to scoring by punishment score (A1B1), group with problem solving learning model with correct score scoring (A1B2), group with learning model directly to the punishment score scoring (A2B1), and the group with direct learning model with correct score scoring (A2B2). Each group took 20 random students who will be sampled in this study so that the total sample of this study was 80 students.

Based on the data of chemistry's students learning outcomes at HOTS level that has been obtained from the experiments that have been done, it is known that the students' lowest score is 26 and the highest score is 70 . The general frequency distribution tabulation can be seen in the following table.

Table 2. Analysis of HOTS Chemical Ability Results of students 


\begin{tabular}{ccccccccc}
\hline $\begin{array}{c}\text { Distribution } \\
\text { of } \\
\text { Experiment }\end{array}$ & \multicolumn{8}{c}{ Group Data } \\
\cline { 2 - 9 } & $\mathrm{A}_{1}$ & $\mathrm{~A}_{2}$ & $\mathrm{~B}_{1}$ & $\mathrm{~B}_{2}$ & $\mathrm{~A}_{1} \mathrm{~B}_{1}$ & $\mathrm{~A}_{2} \mathrm{~B}_{1}$ & $\mathrm{~A}_{1} \mathrm{~B}_{2}$ & $\mathrm{~A}_{2} \mathrm{~B}_{2}$ \\
\hline Mean & 52,68 & 47,25 & 52,58 & 47,35 & 58,5 & 46,65 & 46,85 & 47,85 \\
\hline St. Deviation & 11,44 & 12,04 & 11,08 & 12,41 & 8,275 & 10,47 & 11,34 & 13,68 \\
\hline Max Score & 70 & 67 & 70 & 67 & 70 & 63 & 63 & 67 \\
\hline Min Score & 30 & 26 & 30 & 26 & 44 & 30 & 30 & 26 \\
\hline
\end{tabular}

Before the data are analyzed through hypothesis analysis test, then the test is done by the analysis of prepaid test. This test is divided into two parts, namely data normality test and data homogeneity test. This test aims to determine whether the data obtained from the study results derived from the population is normally distributed or not.

Normality test used in this study using Liliefors test at significance level $\alpha=$ 0.05 while the homogeneity test data is done to determine whether the data has the same variance value. In this research homogeneity test is done by using F-test and Barlett-test.

Here is the prerequisite test in this research.

Table 3. Data Normality Test Results

\begin{tabular}{cccccc}
\hline Number & Group & $\begin{array}{c}\text { Number of } \\
\text { Sample }\end{array}$ & $\mathrm{L}_{\text {calculate }}$ & $\mathrm{L}_{\text {table }}$ & Conclusion \\
\hline 1 & A1 & 40 & 0,071 & 0,14 & Normal \\
\hline 2 & A2 & 40 & 0,128 & 0,14 & Normal \\
\hline 3 & B1 & 40 & 0,081 & 0,14 & Normal \\
\hline 4 & B2 & 40 & 0,123 & 0,14 & Normal \\
\hline 5 & A1B1 & 20 & 0,098 & 0,19 & Normal \\
\hline 6 & A1B2 & 20 & 0,147 & 0,19 & Normal \\
\hline 7 & A2B1 & 20 & 0,122 & 0,19 & Normal \\
\hline 8 & A2B2 & 20 & 0,136 & 0,19 & Normal \\
\hline
\end{tabular}

Table 4. Homogeneity Test Results on Research Data

\begin{tabular}{cccccccc}
\hline \multirow{2}{*}{ Numb. } & \multirow{2}{*}{ Group } & \multicolumn{3}{c}{$\mathrm{F}$ Value } & \multicolumn{2}{c}{$x^{2}$ Value } & \multirow{2}{*}{ Conclusion } \\
\cline { 3 - 6 } & & $\begin{array}{c}\mathrm{F} \\
\text { calculate }\end{array}$ & $\mathrm{F}_{\text {table }}$ & $x_{\text {count }}^{2}$ & $x_{\text {table }}^{2}$ & \\
\hline 1 & A1 dan A2 & 1,108 & 1,70 & - & - & Homogeneous \\
\hline 2 & B1 dan B2 & 1,255 & 1,70 & - & - & Homogeneous \\
\hline 3 & $\begin{array}{r}\text { A1B1, A1B2, } \\
\text { A2B1, A2B2 }\end{array}$ & - & - & 4,778 & 7,82 & Homogeneous \\
\hline
\end{tabular}


Hypothesis testing analysis is carried out with the aim to prove the truth of the research hypothesis that has been made previously. Hypothesis testing in this study uses a two-way variance analysis (ANAVA 2-road) technique which includes three components of testing, namely the main effect, interaction effect, and simple effect.

The main effect test is oriented toward the students's learning result data at the HOTS level in the student group by using the learning model (A), the problem solving model (A1) and the direct learning model (A2) and the students's chemical HOTS ability in the group with scoring type formative test (B) by punishment score (B1) and correct score (B2).

The effect of interaction is done by observing the influence between the two variables to the dependent variable that is the application of learning model (A) and the type of scoring of multiple choice formative test (B) to the chemistry student's HOTS ability. When there is an interaction between the independent variables compared to the dependent variable then proceed to testing the simple effect (simple effect) by using the t-dunnet test to determine groups that have higher results compared to other groups.

The criteria used in this test at the significance level $\alpha=0.05$ is that if the

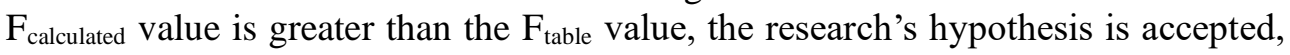
on the contrary if the $F_{\text {calculated }}$ value is smaller than the $F_{\text {table }}$ value, then hypothesis is rejected. The following table results of ANAVA test calculations that have been made in this research.

Table 5. ANAVA Test Results 2 Road

\begin{tabular}{|c|c|c|c|c|c|}
\hline \multirow{2}{*}{$\begin{array}{l}\text { source of } \\
\text { variance }\end{array}$} & \multirow{2}{*}{ JK } & \multirow{2}{*}{ db } & \multirow{2}{*}{ RJK } & \multirow{2}{*}{$\mathbf{F}_{\mathbf{o}}$} & $\mathbf{F}_{\text {Table }}$ \\
\hline & & & & & $\alpha=0,05$ \\
\hline Between A & 588,613 & 1 & 588,613 & 4,769 & 3,968 \\
\hline Between B & 546,013 & 1 & 546,013 & 4,424 & 3,968 \\
\hline Interaction $\mathrm{AB}$ & 825,612 & 1 & 825,612 & 6,689 & 3,968 \\
\hline Inside & 9380,650 & 76 & 123,430 & - & - \\
\hline Total & 11340,888 & 79 & - & - & - \\
\hline
\end{tabular}

Based on ANOVA test result analysis in the above table, it can be seen that the interaction between variables at significance level $\alpha=0,05, \mathrm{~F}_{\mathrm{O}}=6,689>\mathrm{F}_{\mathrm{tab}}=$ 3,968 which means there is interaction between learning model and scoring type of multiple choice formative test against the students's High Order Thinking Skills ability on chemistry lessons.

Other results that are also seen based on the ANAVA test results in the table above, show that at the significance level $\alpha=0.05$, the value of $\mathrm{F}_{\mathrm{O}}=4.769>\mathrm{F}_{\mathrm{tab}}=$ 3.968 which means that there are differences in students's HOTS abilities taught using problem solving learning models and students are taught using the direct learning model. After a one-party test with the formula $\mathrm{t}_{0}(\mathrm{~A})=\sqrt{ } 4,769=2.183>\mathrm{t}_{\text {tab }}$ $=\mathrm{t}(0.05 ; 76)=1.667$ which means $\mathrm{H}_{0}$ is rejected. This means the value of HOTS ability is higher by using problem solving learning model than by using direct learning model.

This happens because the use of problem solving model is able to give 
positive effect to students such as improving students's learning motivation in class, able to enliven learning atmosphere in the class through a series of learning stages that in principle require students to be proactive to the material being taught.

In learning, students are able to communicate actively and massively between students and teachers with regard to the learning problems being discussed. It is then gives awareness of learning to students, encouraging students in learning and trying to understand each indicator of the material in each learning is done so that the results obtained can increase as expected.

The findings are then in accordance with the results of research conducted by Maharani (2015), which explains that learning with problem solving model can develop positive influence among students and also able to develop learning activities in the classroom to give emphasis to students in order to participate actively in class.

Another research which is also similar to the results of this study is the results of research conducted by Widha (2015), which explains that learning with problem solving model is not only able to involve students actively in understanding the concept but also increase student involvement in responding to answers, responding, and solve problems through discussion activities conducted, so that students not only skilled in answering questions, but also skilled in providing reasons for the results obtained.

The results of the analysis on the second variable, namely the type of scoring based on the ANOVA test results in table 4, shows that at the significance level $\alpha=$ 0.05 , the value of $F_{O}=4.424>$ the value of $F_{t a b}=3.968$, which means that there is a difference in HOT chemical ability between students with formative test scoring by the punishment score and the student with the scoring formative test by correct score. Next is tested by one party with the formula $t_{0}(A)=\sqrt{ } 4,424=2,103>t_{\text {tab }}=t$ $(0,05,76)=1,667$ which means $H_{0}$ is rejected. This means higher HOT capability results by using formative test scores on a punishment score rather than by using a correct score formative test.

This is because the scoring by punishment score is able to motivate students in learning because of the emphasis in the form of reduction of the value of the wrong answer when answering the question so that students are more careful in answering questions. Other things found were the students in the group with the scoring by punishment score, tend to be longer in doing the questions than the students in the group with correct score scoring so that the impact on the strengthening of student concentration in working on the problem.

This is consistent with the findings by Khaeruddin (2016), which explains that punishment scores can make students focus more on the test items, be more careful in working on answers, and try to keep the emotional situation of the students under control so that they do not affect students'sstudents's concentration when choosing the right answer option.

Other research that is relevant to the results of this study is a research conducted by Slamet (2014), which explains that the assessment in punishment score has a positive impact on students themselves, including forming the personality of students so that discipline in answering questions, reducing students's bad habits in guessing answers and awaken the students to the mistake when working on the problem.

Unlike correct score scoring, this scoring does not emphasize the students to 
be careful in answering the problem because the scoring is likely to trigger students to do speculation in guessing the answer. This is then affects the teachers also, because teachers are not able to distinguish between students who answered the matter correctly with the results of analysis of his thoughts with students who answered the problem because guessing so that the impact on the tendency of students do not learn to understand the material given.

The presence of scoring by punishment score gives different colors to the students in answering the problem because it is able to minimize the shortcomings in scoring correct score in improving students HOT ability on chemistry lesson

\section{CONCLUSION}

Based on the results of the calculation analysis of hypothesis testing and discussion, there are several conclusions in this study, namely (1) problem solving learning models are more effectively applied than direct learning models in enhancing HOT students's abilities in chemistry lessons, (2) punishing scoring score is more effective in improving the ability of HOT students in chemistry lessons than scoring by correctly score and (3) there are the effect of interaction between problem solving learning models and scoring type of multiple choice formative tests on HOT ability of students in chemistry subjects.

\section{REFFERENCE}

Kerlinger, Freed N. Principles of Behavioral Research. Yogyakarta: Gajah Mada University Press, 2014.

Khaeruddin, "Scoring Techniques of Multiple Choice Model Objective Tests," Journal Madaniah, Vol. 2, Edition 11, 2016

Kusaeri.Eliminating the Guessing Element in the Multiple Choice Test. Jogjakarta: Limas, 2010.

Latifah, Sitti. "Study on the Use of Problem Solving Methods," Journal of Chemical Education, Vol. 3, 2014.

Maharani HR, "Humanistic Matematic Learning With Problem Solving Assisted Interactive Compact Disk to Improve Creative Thinking Ability," International Journal of Education Research, Vol. 3, No.1, 2015

Naga, Dali Santun. Theoretical Sector on Mental Measurement. Jakarta: PT NagaraniCitrayasa, 2013.

Slamet and SamsulbMaarif, "The Influence of Multiple Choice Association Test Forms with Reward and Punishment Score on High School Students's Mathematics Learning," Scientific Journal of Mathematics, Vol. 3, No.1, 2014

WidhaNurSanti, "The Effectiveness of Problem Solving and Problem Posing Models with Cooperative Settings in Mathematics Learning," Journal of Mathematics Education Research, Vol. 2, No.1, 2015 